\title{
EDUCAÇÃO EM SAÚDE PARA PROFISSIONAIS DA EDUCAÇÃO SOBRE PRIMEIROS SOCORROS: RELATO DE EXPERIENCIA
}

\section{HEALTH EDUCATION RELATED TO FIRST AID FOR EDUCATORS: EXPERIENCE REPORT}

\section{RESUMO:}

A necessidade de desenvolvimento de ações sobre primeiros socorros direcionadas a educadores tornou-se extremamente necessária, visto que os acidentes ocorrem em maior parte nas escolas ou a caminho destas. Este trabalho teve como objetivo relatar o trabalho de educação em saúde realizado com profissionais da educação, realizado por meio de oficinas durante a Operação RONDON 2017. Os temas trabalhados foram: "Primeiros socorros no âmbito escolar", "Orientação sobre primeiros socorros aos educadores" e "Prevenção de acidentes". Utilizou-se um questionário de perguntas antes e após as palestras educativas. Os resultados do presente estudo mostraram a necessidade de adocão de práticas educativas sobre primeiros socorros com a participação ativa dos educadores. Conclui-se que ensinamentos sobre primeiros socorros devem ser realizados rotineiramente com os educadores para execução do atendimento emergencial, podendo reduzir a gravidade de acidentes e prevenir maiores danos.

Palavras chave: Educação em saúde; Promoção de saúde; Primeiros socorros.

\begin{abstract}
:
The development of first aid actions directed to educators has become extremely necessary as accidents occur mostly in or on the way to schools. This paper aimed to report the health education work carried out with education professionals through workshops during the 2017 RONDON Operation. The themes worked on were: "First Aid at School", "Guidance on First Aid to Educators" and "Accident Prevention". A questionnaire was used before and after the educational lectures. The results of the present study showed the need to adopt first aid educational practices with the active participation of educators. Therefore, we concluded that trainings on first aid should be routinely performed with educators to enable them to provide emergency care, reducing the severity of accidents and preventing further damage.
\end{abstract}

Keywords: Health education; Health promotion; First aid.

\footnotetext{
*Graduação. Universidade Estadual do Norte do Paraná (UENP), Jacarezinho - PR, Brasil. E-mail: vagnerpcamposjr@gmail.com ${ }^{* *}$ Aluna de Graduação da Universidade Estadual do Norte do Paraná (UENP), Jacarezinho - PR, Brasil. E-mail: aline.acarvalho@hotmail.com ${ }^{* * *}$ Aluna de Graduação da Universidade Estadual do Norte do Paraná (UENP), Jacarezinho - PR, Brasil. E-mail: geovanaraminelli96@hotmail.com ${ }^{* * * *}$ Professora da Universidade Estadual do Norte do Paraná (UENP), Jacarezinho - PR, Brasil. E-mail: sibelliolivieri@hotmail.com
} 


\section{Introdução}

A escola é o ambiente em que comumente ocorrem acidentes, de forma que atinge aproximadamente 6 a 13\% das crianças (OLIVEIRA, 2000; DONOSO; CHIANCA, 2002). Entre as ocorrências mais comuns, estão sangramentos (45\%), desmaios (18\%), fraturas (14\%), avulsão dental (12\%), convulsão (8\%) (OLIVEIRA et al., 2013), além de agressão aos colegas (9\%) (BESSA; DE SOUZA VIEIRA, 2001). Em geral, falta de estrutura da escola ou falta de conhecimento dos responsáveis pode oferecer riscos ao aluno no ambiente escolar (VELDE et al., 2007; CARDOSO, 2008).

Devido a estes fatores, a segurança no espaço escolar, no que tange ao ambiente físico, emocional e psicológico, é objeto de constante preocupação de responsáveis, professores e direção da escola (LIBERAL et al., 2005). Além disso, o fato de crianças e adolescentes passarem aproximadamente um terço do dia na escola ou no caminho em direção a ela exige que a mesma atue na promoção de saúde e prevenção de acidentes (LIBERAL et al., 2005), e, ainda, de estar preparada para providências emergenciais nos casos de ocorrência desses eventos (RIBEIRO, 2011).

Em um acidente, uma das maiores dificuldades se refere à realização eficaz dos primeiros socorros, os quais devem ser feitos a fim de manter a função vital do indivíduo e evitar uma piora no estado do mesmo (PERGOLA; ARAUJO, 2008). Em situações de emergência pré-hospitalar, pode haver redução da morbidade e mortalidade se a primeira ajuda for prestada por leigos com treino nesta área. Porém, devido à falta de informações básicas, desde "a manipulação incorreta da vítima e até a solicitação desnecessária do socorro especializado em emergência" (FIORUC et al., 2008) podem acarretar inúmeros problemas. Alguns estudos têm mostrado um déficit acentuado dos profissionais da instituição em relação a situações críticas, como parada cardiorrespiratória (PCR) (BERNARDES; MACIAL; DEL VECCHIO, 2007).

Dessa forma, professores necessitam estar orientados para atuar nos primeiros socorros, devido ao primeiro atendimento possibilitar o salvamento de vidas (SENA; RICAS; VIANA, 2008; NETO et al., 2017). Para isso, é necessário que pais, funcionários, professores de escolas tenham um curso de suporte básico de vida, para saber agir diante das situações de risco (CARVALHO, 2008). O conhecimento em relação aos acidentes que envolvem crianças, assim como a importância do manejo adequado, contribui para diminuir os traumas físicos e emocionais vivenciados pelas mesmas (PATRÍCIO et al., 2013).

Frente a essas diversidades, a prevenção pode ser o caminho mais eficaz para reduzir os altos índices de acidentes na infância. Para tanto, é preciso que se desenvolvam programas educacionais que promovam melhoria na qualificação profissional dos indivíduos atuantes no mercado de trabalho. O presente artigo tem como objetivo descrever a aplicação de uma oficina em primeiros socorros para professores e funcionários da educação.

\section{Materiais e métodos}

O relato de experiência do presente estudo foi realizado no município de Wenceslau Braz PR durante a Operação RONDON 2017, considerada um projeto de extensão que ocorreu no Estado Paraná cujo objetivo foi capacitar agentes multiplicadores do conhecimento. Em outras palavras, fazer com que o conhecimento seja disseminado, transformando a realidade local.

Diante disso, a população constituiu-se de profissionais representantes de todas as escolas do município que atuavam tanto na área pedagógica quanto na área de serviços gerais, ficando a amostra definida em 15 profissionais, que concordaram em participar do estudo e assinaram o Termo de Consentimento Livre e Esclarecido (TCLE). 
Os cursos foram ministrados em quatro encontros. No primeiro, foram dadas explicações referentes à pesquisa e coleta de assinatura no TCLE dos educadores que aceitaram participar do projeto. Posteriormente, foi aplicado o questionário "O leigo em situações de emergência", e, em seguida, uma oficina foi realizada sobre anatomia básica, cinemática do trauma, verificação de sinais vitais, números emergenciais.

No segundo encontro, o assunto abordado foi atendimento inicial à vítima (passos A, B, C, D, E), desobstrução de vias aéreas, rolamento $90-180^{\circ}$; no terceiro, sangramentos, ferimentos, fraturas, convulsão, febre, desmaios, queimaduras; e no quarto encontro, foram abordados temas como incêndio escolar e parada cardiorrespiratória. Além disso, foi proposta uma simulação geral de incêndio e de situações que poderiam vir a ocorrer no ambiente escolar.

O objetivo dessa atividade foi relembrar todo o aprendizado adquirido durante os quatro dias e avaliar os profissionais participantes em relação à decisão a ser tomada quando a situação requer primeiros socorros. No último dia, foi aplicado novamente o questionário "O leigo em situações de emergência". Em todos os encontros, os temas eram expostos e explicados para que os educadores pudessem praticar as manobras, posteriormente. O processamento dos dados coletados foi realizado por meio de tabelas produzidas pelos programas Software Word 2017 e Excel 2017.

Para avaliação do nível e conhecimento dos profissionais, um questionário referente ao suporte básico de vida (SBV) foi utilizado (PERGOLA; ARAUJO, 2009), tendo sido aplicado no primeiro dia de intervenção - antes que fosse exposta qualquer informação - e no quarto/último dia - após o término da oficina. Os aplicadores foram os alunos e professores responsáveis pela oficina. $O$ questionário utilizado sobre $\mathrm{o}$ conhecimento do SBV foi composto por 13 questões, sendo 10 de múltipla escolha. As questões objetivas avaliaram se o indivíduo sabe como agir em situações de emergência, trazendo perguntas em relação à verificação de sinais vitais, ação a ser tomada quando a vítima está desacordada, movimentação em bloco e outros detalhes a serem observados na vítima. Já as questões abertas indagaram se a pessoa que estava respondendo teve treinamento de primeiros socorros e vivenciou alguma situação em que alguém precisava de socorro médico. Caso a pessoa tenha vivido alguma situação que necessitasse de socorro, solicitava-se que ela descrevesse a ação que tomou. Além disso, foi perguntado quais os números dos telefones emergenciais da cidade.

\section{Resultados}

Após a observação dos dados referentes aos educadores do município, verificouse que a média da idade era de aproximadamente 38,8 anos. Com relação ao gênero, $67 \%$ eram mulheres, sendo $20 \%$ homens e $13 \%$ não responderam a essa questão. Notou-se, também, que $47 \%$ possuíam ensino superior completo, $6 \%$ tinham ensino superior incompleto ou em andamento, e 47\% não identificaram o nível de escolaridade. Além disso, $87 \%$ nunca haviam participado de um treinamento em primeiros socorros, e que apenas $13 \%$ haviam participado.

Ao serem indagados sobre se estavam ou não preparados para atuar em situações que exigem conhecimentos de primeiros socorros, notou-se que $100 \%$ não se encontravam. Ao final da intervenção, viu-se que esse número reduziu, pois apenas $23 \%$ dos entrevistados não estavam preparados. 
Tabela 1 - Distribuição das questões de respostas individuais.

\begin{tabular}{|c|c|c|c|c|}
\hline \multirow{3}{*}{ QUESTÃO } & \multicolumn{4}{|c|}{ Avaliação } \\
\hline & \multicolumn{2}{|c|}{ ANTES } & \multicolumn{2}{|c|}{ APÓS } \\
\hline & SIM (\%) & NÃO (\%) & SIM (\%) & NÃO (\%) \\
\hline $\begin{array}{l}\text { Você já teve algum tipo de treinamento em primeiros } \\
\text { socorros? }\end{array}$ & 13 & 87 & 92 & 8 \\
\hline $\begin{array}{l}\text { Se sim, onde foi esse treinamento? E, você acredita estar } \\
\text { preparado(a) para prestar primeiros socorros em qualquer } \\
\text { tipo de situação? }\end{array}$ & 0 & 100 & 77 & 23 \\
\hline $\begin{array}{l}\text { Você já viu alguma pessoa desacordada necessitando de } \\
\text { socorro médico? }\end{array}$ & 33 & 67 & 15 & 85 \\
\hline Você sabe verificar a presença de sinais vitais? & 73 & 27 & 92 & 8 \\
\hline $\begin{array}{l}\text { Você sabe qual o número de emergência da cidade de } \\
\text { Wenceslau Braz - PR? }\end{array}$ & 60 & 40 & 77 & 23 \\
\hline
\end{tabular}

Fonte: Os autores.

Tabela 2 - Distribuição da assertividade em relação ao atendimento inicial à vítima.

\begin{tabular}{|c|c|c|c|c|}
\hline \multirow{3}{*}{ ASSUNTO RELACIONADO Ȧ QUESTÃO } & \multicolumn{4}{|c|}{ Avaliação } \\
\hline & \multicolumn{2}{|c|}{ ANTES } & \multicolumn{2}{|c|}{ APÓS } \\
\hline & $\mathbf{n}$ & $\%$ & $\mathbf{N}$ & $\%$ \\
\hline \multicolumn{5}{|l|}{ Identificação de sinais vitais } \\
\hline Correto & 8 & 73 & 11 & 92 \\
\hline Parcialmente correto & 1 & 9 & 0 & 0 \\
\hline Incorreto & 2 & 10 & 1 & 8 \\
\hline \multicolumn{5}{|l|}{ Medida a ser tomada quando a pessoa está desacordada } \\
\hline Correto & 10 & 67 & 8 & 62 \\
\hline Parcialmente correto & 3 & 20 & 5 & 38 \\
\hline Incorreto & 2 & 13 & 0 & 0 \\
\hline \multicolumn{5}{|l|}{ Ação a ser feita antes de pedir ajuda } \\
\hline Correto & 14 & 93 & 12 & 92 \\
\hline Incorreta & 1 & 7 & 1 & 8 \\
\hline \multicolumn{5}{|l|}{ Número de emergência da cidade } \\
\hline Correto & 1 & 11 & 6 & 60 \\
\hline Parcialmente correto & 7 & 78 & 4 & 40 \\
\hline Incorreto & 3 & 11 & 0 & 0 \\
\hline \multicolumn{5}{|l|}{ Detalhes da vítima a ser informado ao socorro } \\
\hline Correto & 8 & 53 & 11 & 85 \\
\hline Parcialmente correto & 2 & 13 & 2 & 15 \\
\hline Incorreto & 5 & 33 & 0 & 0 \\
\hline \multicolumn{5}{|c|}{ Necessidade de realizar atendimento com precisão e curto intervalo de tempo } \\
\hline Correto & 7 & 47 & 8 & 62 \\
\hline Parcialmente correto & 5 & 33 & 5 & 38 \\
\hline Incorreto & 3 & 20 & 0 & 0 \\
\hline \multicolumn{5}{|l|}{ Ação a ser feita com suspeita de quebra na coluna cervical } \\
\hline Correto & 14 & 93 & 13 & 100 \\
\hline Incorreto & 1 & 7 & 0 & 0 \\
\hline \multicolumn{5}{|l|}{ Mobilização em bloco } \\
\hline Correto & 10 & 67 & 12 & 92 \\
\hline Incorreto & 4 & 27 & 1 & 8 \\
\hline \multicolumn{5}{|c|}{$\begin{array}{l}\text { Posicionamento da vítima caso ela esteja desacordada e sem suspeita de lesão } \\
\text { na coluna }\end{array}$} \\
\hline Correto & 4 & 27 & 5 & 38 \\
\hline Incorreto & 11 & 73 & 8 & 62 \\
\hline
\end{tabular}

Fonte: Os autores. 
Além disso, os educadores (Figura 1) relataram experiências vividas no contexto escolar que envolveram utilização dos primeiros socorros. Muitos afirmaram não saber o que fazer mediante situação e relataram relevância sobre o tema. Ao final, os participantes concluíram estarem aptos a prestar os primeiros socorros e que a experiência vivida era enriquecedora.

Os rondonistas - responsáveis por aplicar a oficina - relataram a importância do tema e se emocionaram ao final da oficina em saber que o objetivo proposto foi concluído. Alguns disseram se surpreender com o desafio e a capacidade de utilização de materiais recicláveis para a realização de materiais de primeiros socorros, como por exemplo o papelão. Também descreveram que a simulação de incêndio proposta foi enriquecedora para os universitários que não sabiam como agir mediante essa situação. Isso possibilitou troca de conhecimento entre os integrantes da equipe.

Figura 1 - Participantes e rondonistas na execução da oficina de primeiros socorros.

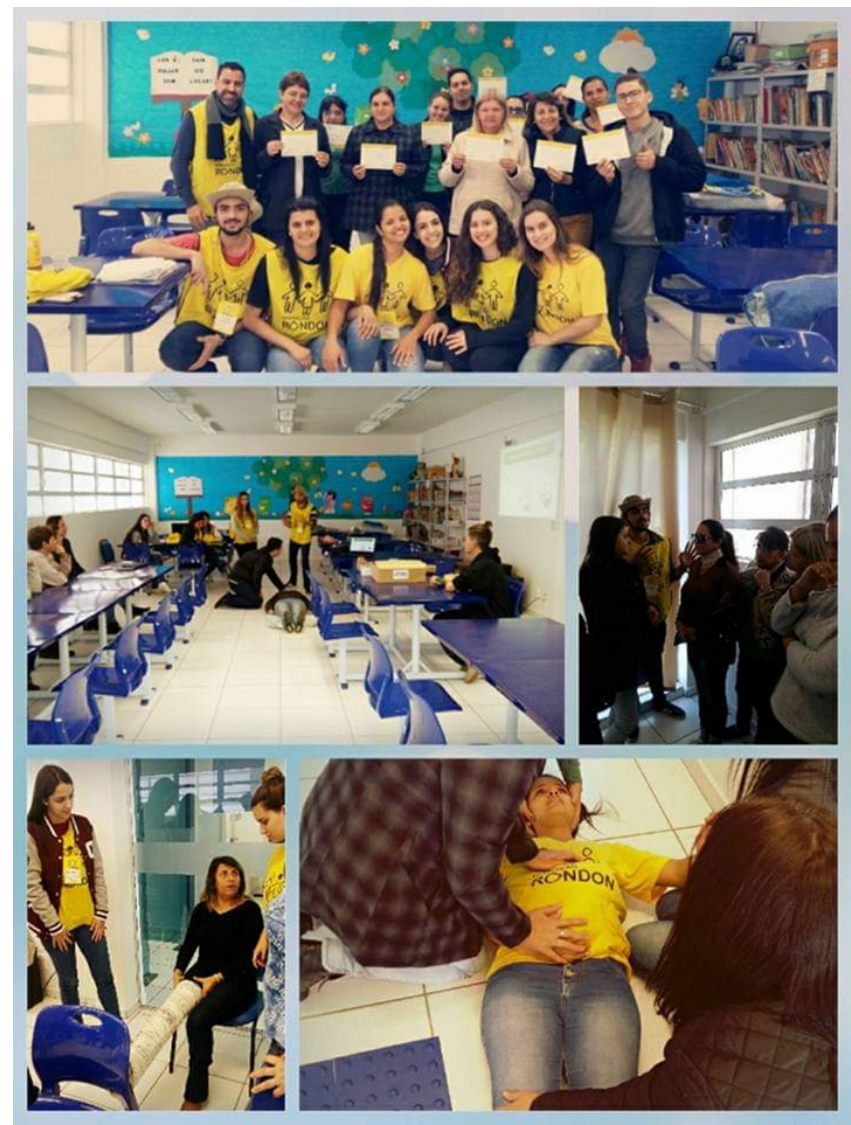

Fonte: Os autores.

\section{Discussão}

Os primeiros socorros são procedimentos de urgência, iniciais, prestados a uma vítima que sofreu algum tipo de acidente (OLIVEIRA, 1999). No ambiente escolar, encontram-se diversas situações em que o professor possa vir a utilizar das técnicas do preatendimento hospitalar, pois momentos de lazer ou de aprendizagem como recreio e aulas de educação física tornam-se lugares propícios para a ocorrência de acidentes (LIBERAL; AIRES; OSÓRIO, 2005). Por isso, um professor apto a observar o ambiente e identificar fatores de riscos torna-se necessário para proteção da saúde dos escolares (CARDOSO; REIS; LERVOLINO, 2008). 
Neste estudo, observou-se que a porcentagem daqueles que afirmaram saber identificar a presença de sinais vitais não condiz com a porcentagem de acertos do mesmo. Muitas vezes, a falta de informação pode acarretar diversos problemas, principalmente quando se fala em atendimento emergencial. Por exemplo, o pânico ao ver o acidentado pode levar o indivíduo a agir por impulso - mesmo que ele não tenha conhecimento suficiente - piorando o estado em que a vítima se encontra. O estado de pânico pode fazer com que o professor, ao atender o aluno acidentado, deixe de cuidar das outras crianças, o que pode vir a facilitar a ocorrência de outro acidente (FIORUC et al., 2008; RIBEIRO, 2011).

Um fato interessante a ser relatado refere-se ao conhecimento de números emergenciais, em que muitos citaram o telefone da polícia do município. Estudos anteriores também relataram que a população tem mais conhecimento do número do serviço da polícia militar do que o de emergência (BATISTA et al., 2013). Apesar de não ser considerado o contato de serviço de pronto-atendimento, a citação do telefone da polícia como emergencial foi considerada uma resposta parcialmente correta, pois o serviço prestado pelo órgão não é diretamente um serviço de pronto-atendimento (PERGOLA; ARAÚJO, 2008).

Quanto à ação a ser feita diante da suspeita de quebra na coluna cervical, verificou-se que somente após o programa de orientação $100 \%$ dos presentes responderam à questão de maneira correta. Nestes casos, a ação a ser feita é não tocar na vítima ou mobilizá-la em bloco, quando necessário (PERGOLA; ARAÚJO, 2008). Porém, quando questionados sobre a mobilização em bloco, $92 \%$ dos pesquisados responderam corretamente. A relação entre as duas questões deixa explícito que nem todos os que disseram saber o que fazer executariam, de fato, o ato de maneira correta. Por isso, vê-se a necessidade de que os profissionais estejam capacitados para agir frente a situações de risco, com o intuito de evitar que tais situações se atenuem (LEITE, 2013).

O posicionamento da vítima caso ela esteja desacordada e sem suspeita de lesão na coluna deve ser feito, sempre que possível, de maneira lateralizada, a fim de evitar que a vítima aspire líquido ou até mesmo o próprio vômito (CAMBOIN; FERNANDES, 2016). Observou-se, no presente estudo, que os educadores tiveram tanto antes quanto após o programa de orientação um baixo nível de acertos (38\%), pois registrou-se que a maioria dos participantes assinalou como alternativa correta o posicionamento de costas, demonstrando que, muitas vezes, a falta de orientação pode acarretar numa piora de estado da vítima. Esse fato corrobora o achado em outro estudo que afirma que a população detém os conhecimentos de atendimento às vítimas inconscientes, entretanto, são incompletos ou incorretos, fato que pode comprometer tal atendimento (PERGOLA; ARAÚJO, 2008).

Pode-se observar, neste estudo, que o credo popular ou a falta de informação é um dos principais problemas enfrentados na prestação de primeiros socorros no ambiente escolar, visto que os que detêm conhecimento não sabem a hora de aplicá-los, nem o motivo pelo qual usam as técnicas (RIBEIRO et al., 2019). Por isso, é de suma importância que reuniões como essas sejam realizadas com intuito de propiciar a troca de experiências e discussão de medidas de educação em saúde para tal público (MOURA et al., 2018). Também se vê necessidade de que haja um treinamento para os alunos, uma vez que eles podem vir a se deparar com situações que exigem noções básicas de primeiros socorros (CHAVES et al., 2017).

Além disso, este tipo de conhecimento deve ser reforçado constantemente para que o aprendizado seja contínuo e não esquecido. Dessa forma, sugere-se que profissionais que trabalham com educação tenham treinamento, através de programas governamentais ou não, em primeiros socorros, a fim de prepará-los para qualquer acidente ou imprevisto que possa ocorrer com o aluno ou funcionário da escola. 


\section{Conclusão}

Um melhor desempenho foi observado nos educadores após o programa de intervenção. A implantação de um programa de intervenção para levar conhecimento a educadores sobre primeiros socorros em ambiente escolar deveria ser estimulada nas escolas, visto que o assunto é pouco discutido e que os profissionais da educação carecem de informação sobre o atendimento emergencial.

\section{Referências}

BERNARDES, E. L.; MACIEL, F. A.; DEL VECCHIO, F. B. Primeiros socorros na escola: nível de conhecimento dos professores da cidade de Monte Mor. Movimento \& Percepção, v. 8, n. 11, 2007.

BESSA, A. G.; DE SOUZA VIEIRA, L. J. E. Acidentes em crianças no contexto escolaruma visão do educador. Revista Brasileira em Promoção da Saúde, v. 14, n. 1, p. 15$20,2012$.

BATISTA, M. N. P. et al. Nível de conhecimento em primeiros socorros de professores de educação física. EFDesportes. com-Revista Digital, Buenos Aires, ano 18, v. 186, 2013.

CAMBOIN, F. F.; FERNANDES, L. M. Primeiros socorros para o ambiente escolar. Porto Alegre: Evangraf, 2016.

CARDOSO, V.; REIS, A. P.; LERVOLINO, S. A. Escolas promotoras de saúde. Revista Brasileira Crescimento e desenvolvimento humano, v.18, n. 2, p.107-115, 2008.

CARVALHO, F. F. Acidentes Infantis: Relatos de Diretores e Professores do Ensino Fundamental e Análise do Material Didático. 2008. 103p. Dissertação (Mestrado em Educação) - Universidade Estadual Paulista “Júlio de Mesquita Filho", Marília, 2008.

CHAVES, A. F. L. et al. Reanimação cardiopulmonar nas escolas: avaliação de estratégia educativa. Revista Expressão Católica Saúde, v. 2, n. 1, p. 65-72, 2018.

COLLUCCI, C. Acidente infantil ocorre perto de adulto. Folha on-line, São Paulo, v. 3, 2006. Disponível em:

$<$ http://www1.folha.uol.com.br/folha/cotidiano/ult95u123446.shtml $>$. Acesso em: 10 dez. 2017.

DONOSO, M. T. V.; CHIANCA, T. C. M. Condições envolvidas na ocorrência de acidentes em população infantil atendida em um hospital de pronto-socorro de Belo Horizonte. Rev. Med. Minas Gerais, v. 12, n. 1, p. 11-16, 2002.

FIORUC, B. E. et al. Educação em saúde: abordando primeiros socorros em escolas públicas no interior de São Paulo. Revista eletrônica de enfermagem, v. 10, n. 3, 2008.

HAFEN, Q. B.; KARREN, J. K.; FRADSEN, J. K. Primeiros socorros para estudantes. Barueri: Malone, 2002. 
LEITE, A. C. Q. B.; FREITAS, G. B.; MESQUITA, M. M. L. de; FRANCşA, R. R. F. de; FERNANDES, S. C. de A. Primeiros Socorros nas Escolas. Rev. Eletr. Extendere [Internet], v.2, n.1, 2013. Disponivel em: http://periodicos.uern.br/ index.php/extendere/article/viewFile/778/429. Acesso em: 10 dez. 2017.

LIBERAL, E. F.; AIRES, R.T.; OSÓRIO, A.D.A. Escola segura. Jornal de Pediatria, v.81, n.5, p.155-63, 2005.

MOURA, R. L. et al. Primeiros socorros: objeto de educação em saúde para professores. In: CONGRESSO NORTE NORDESTE DE TECNOLOGIAS EM SAUDE, I., 2018, Teresina. Anais eletrônicos... Teresina, 2018.

NETO, N. M. G. et al. Primeiros socorros na escola: construção e validação de cartilha educativa para professores. Acta Paulista de Enfermagem, v. 30, n. 1, p. 87-93, 2017.

OLIVEIRA, J. S. Acidentes em crianças e adolescentes: estudo epidemiológico de saúde escolar em Belo Horizonte, MG. Dissertação (Mestrado) - Faculdade de Medicina, Universidade Federal de Minas Gerais, Belo Horizonte, MG, 2000.

OLIVEIRA, M. Fundamentos do socorro pré-hospitalar. Chapecó-SC: Grifos, 1999.

OLIVEIRA, M.A.; SILVA JUNIOR, C.J.; TOLEDO, E.M. O conhecimento em prontosocorrismo de professores da rede municipal de ensino do Ciclo I de Cruzeiro-SP.

Educação, Cultura e Comunicação, v. 4, n. 7, 2013.

PATRÍCIO, A.C.F.A. et al. Conhecimento dos profissionais que trabalham na educação infantil: prevenção e manejo do trauma. Revista de Enfermagem UFPE, p. 6617-6623, 2013.

PELICIONI, M. C. F.; GIKAS, R. M. Prevenção de acidentes em escolares: proposta de metodologia de diagnóstico para programa educativo. Revista Brasileira Saúde Escola, v.2, n.1, p.23-26, 1992.

PERGOLA, A. M.; ARAUJO, I. E. M. O leigo em situação de emergência. São Paulo: Revista da Escola de Enfermagem da USP, v.42, n.4, p.769-776, 2008.

RIBEIRO, C. S. Os primeiros socorros como uma competência de efetivação dos direitos referentes à vida e à saúde: o desafio do educador infantil. Colóquio Internacional de Educação, v. 1, n. 1., 2011.

RIBEIRO, T. L. et al. Primeiros socorros: conhecimento dos professores de ensino fundamental do município de quixadá em situações de emergência no ambiente escolar. Mostra Interdisciplinar do curso de Enfermagem, v. 3, n. 1, 2019.

SENA, S. P.; RICAS, J.; VIANA, M. R. A. A percepção dos acidentes escolares por educadores do ensino fundamental, Belo Horizonte. Revista Medicina Minas Gerais, v. 18, n. 4 Supl 1, p. S47-S54, 2008.

SILVA, R. C. L.; FIGUEIREDO, N. M. A (Org.). Enfermagem: cuidando em emergência. São Caetano do Sul, SP: Yendis Editora, 2006.

VELDE, S. V. et al. European first aid guidelines. Resuscitation, v.72, n.2, p.240-251, 2007. 